\title{
Information Requirements for Pilots to Execute 4D Trajectories on the Airport Surface
}

\author{
Victor H. L. Cheng* \\ Optimal Synthesis Inc., Los Altos, CA 94022 \\ Anthony D. Andre ${ }^{\dagger}$ \\ Interface Analysis Associates, Gilroy, CA 95020 \\ David C. Foyle \\ NASA Ames Research Center, Moffett Field, CA 94035
}

\begin{abstract}
Trajectory-based operations constitute a key mechanism considered by the Joint Planning and Development Office (JPDO) of the U.S. for managing traffic in high-density or highly complex airspace in the Next-Generation Air Transportation System (NextGen). With this concept applied to surface operations at major airports, current research has been exploring the use of surface 4-dimensional (4D) trajectories, which use required times of arrival (RTAs) at selected locations along the taxi route. The research has explored the use of collaborative automation systems in the control tower and on the flight deck to plan and execute these 4D trajectories to achieve safe and efficient surface operations, and prototype experimental systems for these automation systems have been developed. This paper reports on a study with human-in-the-loop experiments performed using prototype designs of the flight-deck automation system display to achieve two primary objectives: identify information requirements for the pilot to execute 4D trajectories, and investigate usability of the flight-deck display. More specifically, the findings help to identify the information requirements for the pilots, to discover issues related to the general interface design and properties of the display, and to recommend specific improvements that could be made to the design of the display and how it communicates information to the user.
\end{abstract}

\section{Introduction}

$\mathrm{T}$ he Joint Planning and Development Office (JPDO) has developed a Concept of Operations (ConOps) for the Next Generation Air Transportation System ${ }^{1}$ (NextGen). Trajectory-based operations (TBO) constitute a key mechanism of the NextGen ConOps for managing traffic in high-density or high-complexity airspace. Applying this mechanism to surface operations at major airports results in the use of 4-dimensional (4D) trajectories to enable safe and efficient surface operations. When referring to 4D-trajectory (4DT) operations, it is implicitly assumed that there is already agreement between the Air Navigation Service Provider (ANSP) and the flight deck (FD) on a 4D trajectory to be executed; otherwise the notion of 4D trajectories is meaningless. Full 4D trajectories may imply defining 3D spatial position as a function of time. However, practical concepts involving 4D trajectories define required times of arrival (RTAs) at selected locations along the route. For Trajectory-Based Surface Operations (TBSO), the natural locations to specify the RTAs include taxiway intersections, runway intersections, and hold lines. Successful execution of TBSO has to address how a flight controls its movement to achieve the RTAs.

In current-day operations, the ANSP specifies the taxi routes, controls the order of merging at intersections or use of runways, and allows the pilots to provide separation visually. To enhance safety in the face of increasing traffic, the FAA has been introducing new surface surveillance technologies such as Airport Surface Detection Equipment - Model X (ASDE-X) ${ }^{2}$, Automatic Dependent Surveillance - Broadcast (ADS-B) ${ }^{3}$, Airport Movement Area Safety System (AMASS) ${ }^{4}$, and Runway Status Lights ${ }^{5}$. Previous NASA research efforts have developed flightdeck technologies for improving situational awareness and enhancing safety, including the Taxiway Navigation and

\footnotetext{
${ }^{*}$ Principal Scientist, 95 First Street, Suite 240, and AIAA Associate Fellow.

${ }^{\dagger}$ Founding Principal, 6800 Redwood Retreat Road.

${ }^{\ddagger}$ Research Psychologist, Human Systems Integration Division, Mail Stop 262-4.
} 
Situation Awareness (T-NASA) System ${ }^{6,7}$ and the Runway Incursion Prevention System (RIPS) ${ }^{8,9}$. The Surface Management System $^{10}$ (SMS), developed by NASA in cooperation with the FAA, is a valuable decision-support tool for service providers and NAS users for providing situational awareness of the airport traffic ${ }^{11}$.

For TBSO, Surface Operation Automation Research (SOAR) ${ }^{12-15}$ has provided the seminal research in surface 4DT operations in a holistic approach to the problem. SOAR promotes collaborative automation systems for the tower $^{16}$ and the flight deck ${ }^{17-19}$ to enable 4DT operations. With an early prototype of the tower automation to support experimentation, the SOAR concept has been subjected to human-in-the-loop (HITL) evaluation ${ }^{20}$ at the FutureFlight Central (FFC) tower simulator ${ }^{21}$ at NASA Ames Research Center, where some of the human-factors concerns were studied ${ }^{22,23}$.

Recent research dedicated to the pursuit to realize TBSO includes NASA in-house and NASA-sponsored activities to develop concepts and technologies for safe and efficient surface operational planning by Rathinam et al. ${ }^{24}$ and Tsao et al. ${ }^{25}$. Foyle et al. ${ }^{26,27}$ have conducted a series of FD human factors studies aimed at determining information requirements for execution of 4D taxi clearances using manual FD speed control. Their results suggest that in order to effectively conduct surface 4D-trajectory clearances under pilot manual control, the future FD may likely require displays to allow pilots to "close the loop" on the aircraft's 4DT speed/time error, as well as indicating the value of both speed-based and time-based information displays.

Jones $^{28}$ has also built on the earlier RIPS technologies to develop FD technologies for collision avoidance. The EUROCONTROL Advanced Surface Movement Guidance and Control System ${ }^{29}$ (A-SMGCS) concept includes research on optimization of airport taxi scheduling ${ }^{30}$. The European Airport Movement Management by A-SMGCS (EMMA) project defined A-SMGCS operational requirements ${ }^{31}$ for the ANSP and FD, and other important services (e.g., communication, navigation, and surveillance (CNS) ${ }^{32}$ ).

The previous SOAR experience in developing the concept for TBSO resulted in prototype experimental systems for both tower automation and FD automation, respectively for planning and executing 4D trajectories. In particular, the prototype FD automation - known as Flight-deck Automation for Reliable Ground Operations (FARGO) provides two modes of automation: (i) automation aid to recommend guidance command to help the pilot navigate the $4 \mathrm{D}$ trajectory, and (ii) fully automatic taxi control. In both cases, pilot displays have been designed to convey the necessary guidance and control information to enable the pilot to perform 4D trajectory tracking. This paper reports on a usability test developed around the FARGO experimental prototype to study the information requirements of the pilot in executing the 4D trajectories under either automation mode. Section II provides an overview of the FARGO system and its displays, followed by description of the usability test and findings in subsequent sections.

\section{Overview of Flight-Deck Automation and Displays}

The SOAR concept is built upon the following coupled assumptions:

1. The FARGO automation system can achieve high-precision taxi to allow the flight to meet any reasonable crossing times at selected points along a pre-specified taxi route on the airport surface.

2. The tower automation system counts on the availability of FARGO's precision-taxi capability to plan efficient and safe operations for the surface traffic.

Figure 1 shows a general aircraft-control block diagram involving the FARGO system, which supports both an auto-taxi mode and a manual mode aided by FARGO automation. The 4D taxi clearance with embedded RTAs is data-linked to the FARGO system. More details of the FD procedure can be found in Ref. 19. The display shows different types of control advisories to the flight crew depending on the automation mode in which FARGO is operating. Figure 2 illustrates the FARGO displays being considered for the SOAR concept. Clearance information down-linked from tower automation is loaded onto the flight computer for processing. The text message is displayed to the flight crew on a display such as the Lower EICAS, and it is also parsed for extraction of the route information to be displayed graphically to the flight crew, who can pre-visualize the route on the Electronic Moving Map (EMM). The concept assumes the availability of a Head-Up Display (HUD) for conveying taxi control information to the pilot, allowing the pilot to maintain an out-the-window view while executing the 4D trajectory. The usability test described below focuses on the use of the HUD for conveying the taxi control information. 


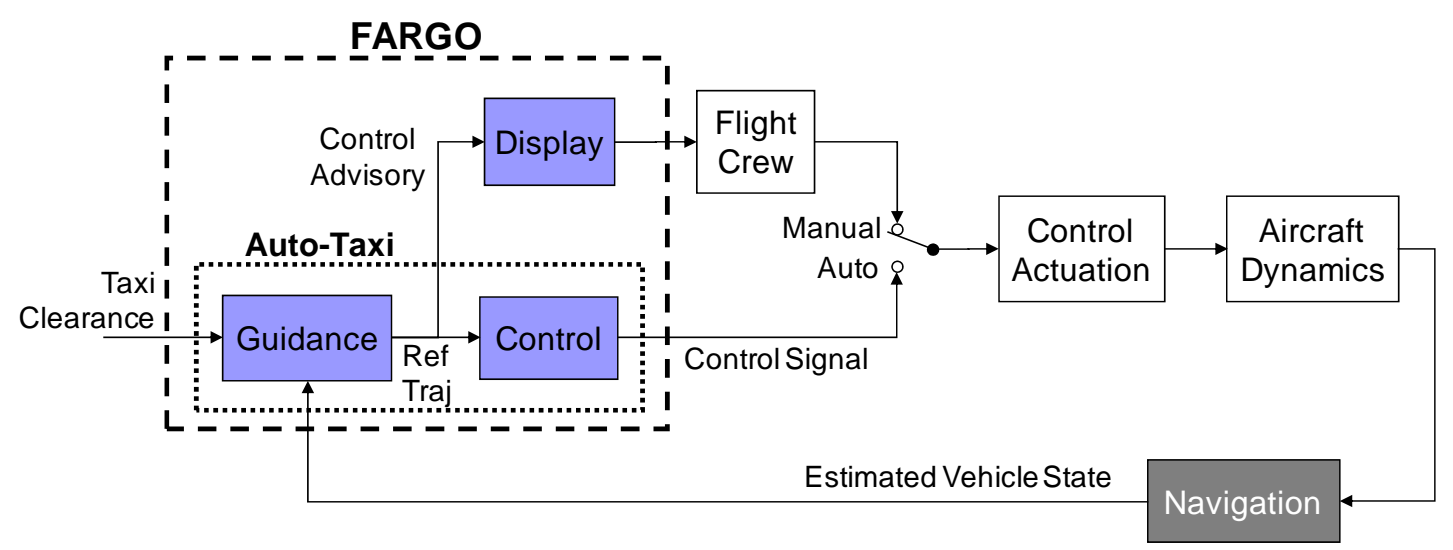

Figure 1. General Block Diagram of Aircraft Control with FARGO Concept

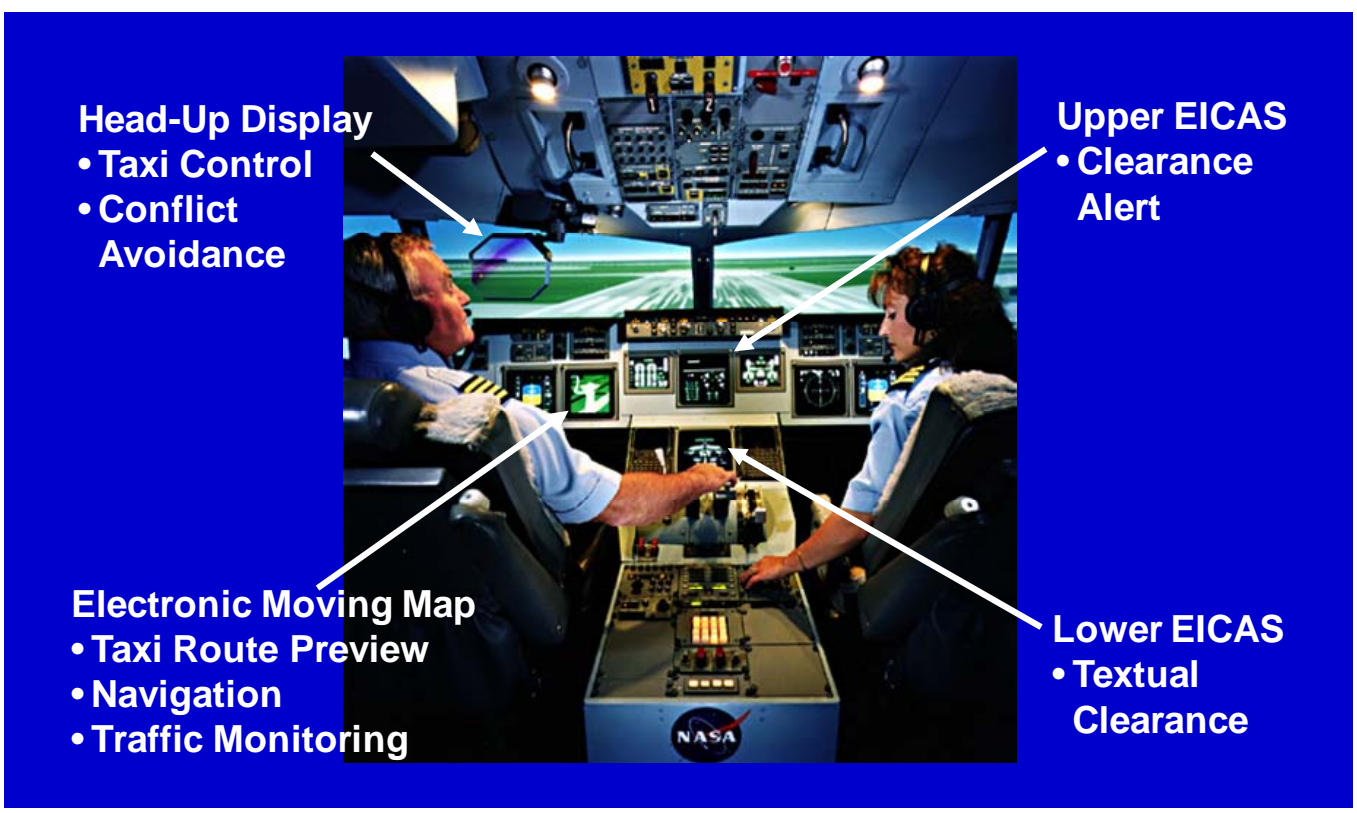

Figure 2. FARGO Pilot-Interface Displays

As the taxi route nominally would contain locations where safety may become a serious concern if the aircraft is unable to achieve the precise timing (e.g., active-runway crossings), the data-linked clearances include "contingency holds" inserted along the route at these locations to give the controller the option of allowing the aircraft to come to a stop if the controller chooses not to clear it beyond any such point. This means that the taxi route in fact consists of a number of segments, each of which needs to be cleared as a separate clearance, and each segment contains a contingency hold at the end except for the final segment. The contingency hold is automatically removed when a subsequent segment is cleared. To allow the pilots the opportunity to pre-visualize the taxi operation, a preclearance would be issued to contain the whole taxi route. The SOAR nominal operational procedure for handling preclearances contains the following events:

- Minutes before the clearance is needed, the tower automation sends FARGO a data-linked preclearance containing taxi route information similar to conventional clearances, with the addition of time constraints where necessary to resolve conflicts with other vehicles and runway usage.

- FARGO would access an airport layout database to convert the preclearance into route-segment information ready for access by the cockpit crew.

- When selected by the pilot, FARGO would display the clearance in both textual and graphical forms, with the crossing constraints appropriately emphasized. If the preclearance involves more than one segment, the display will show the segments with the location of their contingency holds. 
- The interface provides the pilot with options to accept or reject the preclearance. Acceptance of the preclearance can automatically save the route, crossing-constraint, segment and contingency-hold information for the guidance function to access and generate the reference trajectory to drive the display and the control function.

- Acknowledgment of the preclearance is data-linked back to the tower automation to help the controllers keep track of the status.

\section{Study Objectives and Methodology}

\section{A. Objectives}

The purpose of the usability and information requirements study of the FARGO HUD was to identify the information requirements for the pilots to execute the 4D-trajectory operations, to discover issues related to the general interface design and properties of the HUD, and to document specific improvements that could be made to the design of the HUD and how it communicates information to the user.

\section{B. Study Design}

Eight pilots, from the San Francisco Bay Area, were asked to interact with the FARGO HUD taxi system using a simulated flight taxi environment, with the intent of collecting feedback on the design and information conveyed by the interface. Participants were first introduced to the idea of precision taxiing and elements of the FARGO HUD through a slideshow. They then performed a taxi clearance task using the simulator without using the HUD, to (a) familiarize themselves with the simulator controls and (b) start thinking about what information was needed to make the process easier.

After performing trials without the HUD, the FARGO HUD was activated and participants completed additional trials using the simulator controls. They were then asked whether the HUD satisfied their needs as far as what information it was conveying to them. After performing the manual control tasks, participants were then introduced to the Auto-Taxi system, and asked to provide feedback about how the HUD display satisfied their informational needs for monitoring system performance. In summary, all participants were exposed to three conditions during each session in the following order:

1. No FARGO - No HUD was provided to the participant except for a time indicator. Participants were responsible for hitting their marks and holds based on the electronic readout of the taxi plan.

2. Manual Control - The FARGO HUD was visible, and the participant manipulated the flight stick, throttle and pedals to steer the aircraft through the taxi plan.

3. Automatic Control - The FARGO HUD was visible, but control actions were performed by an algorithm simulating an auto-taxi system.

\section{Participants}

The following is a demographic summary of the 8 participants who were included in the study:

- The group is composed of a mix of males $(\mathrm{N}=4)$ and females $(\mathrm{N}=4)$.

- Their age ranged from 37 to 66 years, with a mean age of 46.44 years and a median of 45 years.

- They represent a mix of commercial $(\mathrm{N}=5)$ and private $(\mathrm{N}=3)$ pilots.

- Two of the participants were retired, one 6 months ago from a commercial airline and the other 6 years ago from a corporate airline.

- Their place of work ranged from some of the major U.S. airlines to corporate and private entities.

\section{Test Articles and Setup}

Participants interacted with the FARGO airport taxi HUD system. The HUD was viewed using a desktop PC driving a 21" LCD monitor simulating an "out the window" view overlaid with the HUD, with a second monitor displaying the EMM. As illustrated in Figure 3, The test room was configured with a computer desk and an adjustable chair with a simulated aircraft joystick (used as a tiller) placed on a chair to the right of the participant, a throttle controller placed on a chair to the left of the participant, and rudder pedals placed below the computer workstation. 


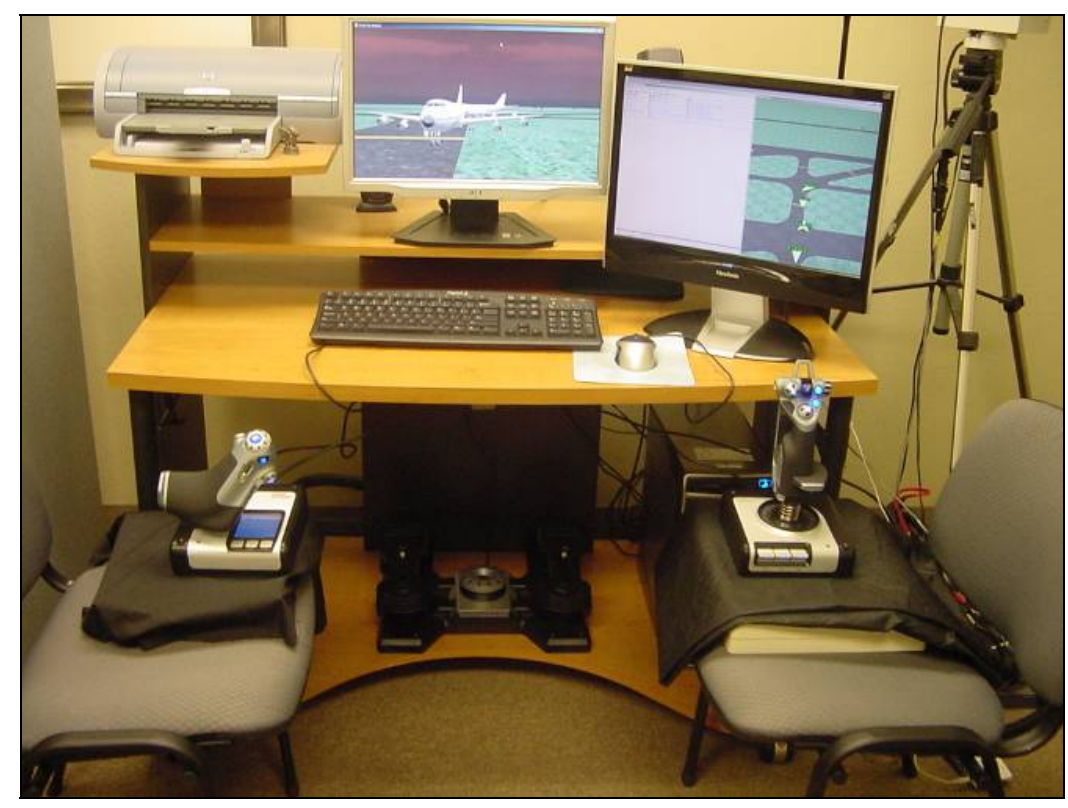

Figure 3. Experimental Setup

A separate control room housed the test administrator and the audio-visual (AV) controller. Between the rooms is a one-way mirror that allows the test personnel to directly view the participant. The computer scan and a video of the participant's face, plus the audio were fed into the control room, mixed, and recorded to a DVR machine. A datalog computer workstation allowed for observational and performance data collection via real-time and postsession video analysis.

\section{E. Data Collection}

Behavioral measures considered in the data collection included body posture, utterances, and hesitations indicative of frustration, effort, complexity, as well as verbal comments made during and following their interaction with the product. In addition to performance and behavioral measures, a variety of subjective ratings were collected. At the end of the first phase, the moderator asked the participant a series of questions in order to uncover any usability issues. In addition, the participant was asked to provide ratings about a variety of different aspects of the HUD.

\section{F. Test Procedure}

The following events/procedures occurred for all 8 participants:

1. The moderator introduced the participant to the FARGO system using a brief PowerPoint presentation on the desktop. The moderator then described the various controls and simulation limitations, and verified that the first mode presented would be No FARGO.

2. The following is a general overview of the protocol for each participant

- Participants were first given a practice trial for the No FARGO mode.

- Participants were then instructed to perform two actual trials where they tried to successfully carry out the instructed clearance.

- During the trial, participants were asked questions about their current route status to determine their awareness and use of the HUD indicators.

- After each trial, participants were asked several more questions and given the opportunity to provide feedback.

- After completing their trials in No FARGO mode, participants were then subjected to the same procedure outlined above with the Manual FARGO mode, followed by observing the Auto FARGO mode.

3. At the end of the session the moderator discussed information requirements, issues associated with various aspects of the user interface, and ways to further improve the user interface. In addition, the moderator asked participants to answer a series of post-interaction questions regarding whether the FARGO system met the requirements of an aircraft taxi control system. 
4. During the session, participant interaction, verbal responses, and ratings following each trial were recorded in real time.

\section{Study Observations and Findings}

Overall, participants found the idea of precision taxiing to be a good one which would greatly increase the overall efficiency of air travel. The FARGO HUD was seen as a crucial component to the idea of precision taxiing, and there was unanimous acknowledgement that precision taxiing would be impossible without it. This suggestion, however, has to be examined by taking the test method into consideration. The test only compared the use of the HUD to the case without the HUD, but did not consider the possibility of other forms of display. Hence this suggestion should be interpreted as some form of display that carried comparable information as that on the HUD should be considered essential for precision taxiing.

The results below are organized by sections of the HUD, ending with various user ratings and comments. Note that not all participants completed all of the same trials and therefore some participants were not asked the same questions for each task. The actual number of participants involved in rating each task is listed as $\mathrm{N}$ below.

\section{A. Manual Control with No HUD/FARGO Display}

The first task was to navigate the clearance instructions. No HUD display was provided for this task; all the participants had to guide them was an electronic copy of the clearance instructions and a clock by which they had to gauge if they were ahead or behind schedule. Participants were directed to only use the EMM as reference and not to pilot the aircraft using the map. Figure 4 contains an illustration of the EMM display. The purpose of this task was to give the participant an idea of what kinds of information a precision taxi system needs to provide its users in the HUD, as well as to allow the participant time to familiarize themselves with the controls for the simulator prior to experiencing the next condition.

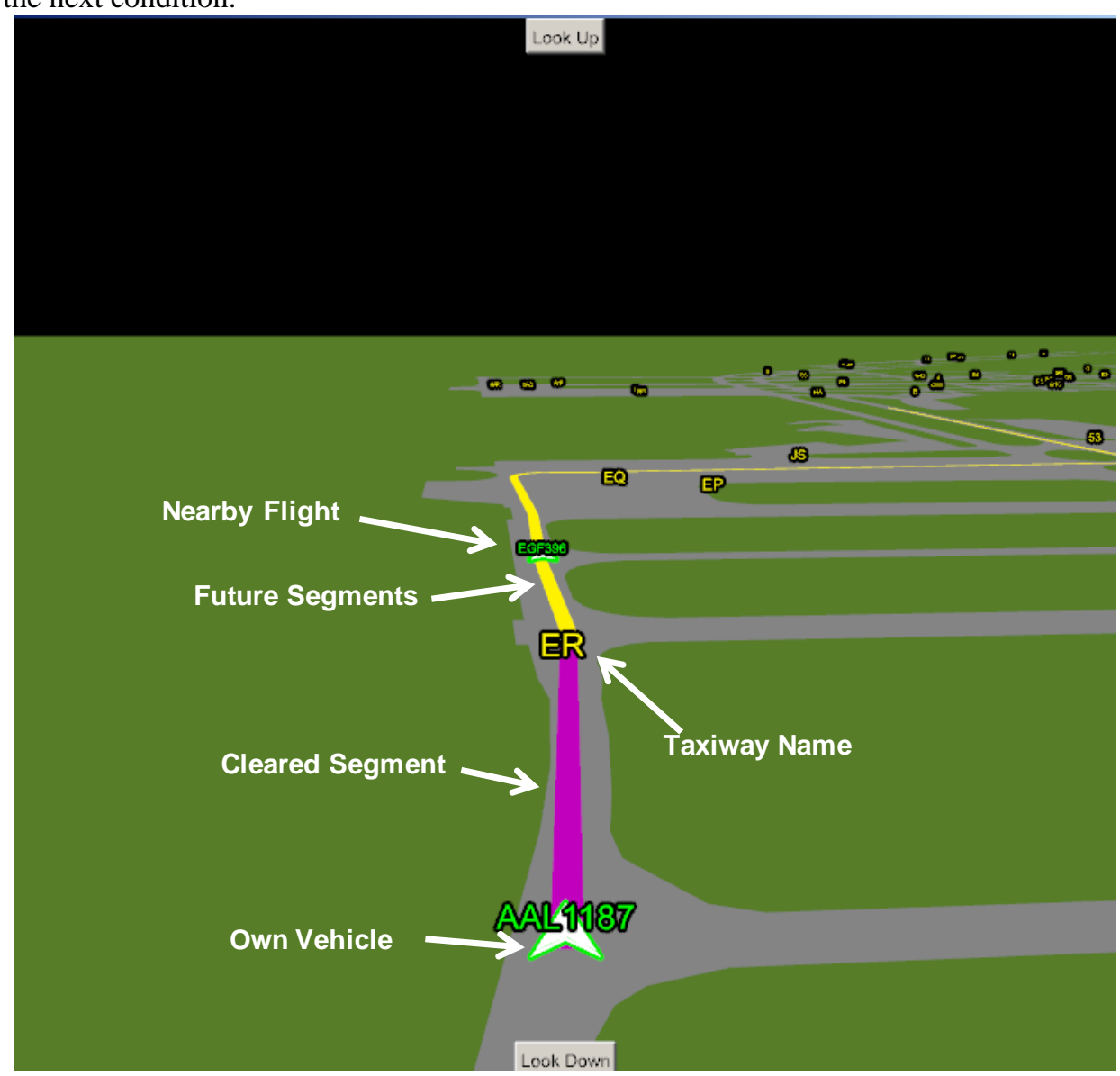

Copyright @ 2008-2009, Optimal Synthesis Inc. Published with Permission.

Figure 4. Sample EMM Display

American Institute of Aeronautics and Astronautics 
Overall, the participants found it relatively easy to identify the correct checkpoints and needs as outlined in the electronic clearance instructions and EMM. What was more difficult was managing the performance of the plane to meet the times and locations on those instructions, given the lack of feedback. While they had a basic understanding of where they should be and at what time, participants stated that to safely maneuver their plane to meet those requirements they would require additional feedback.

The participants most frequently cited ground speed, distance remaining between checkpoints, and throttle up/down indicators as the most important pieces of information to provide the user in this context. Several participants also noted that a graphical representation of the electronic map and clearance instructions would be useful as well, to prevent them from having to constantly shift focus between the EMM and the HUD display.

\begin{tabular}{|l|l|c|}
\multicolumn{1}{|c|}{ Task Ratings: } & \multicolumn{1}{|c|}{ Mean Rating } & N \\
\hline $\begin{array}{l}\text { How easy or difficult was it to navigate the route? } \\
\text { (1=Very Difficult, 5= Very Easy) }\end{array}$ & 2.75 (Neutral) & $\mathrm{N}=6$ \\
\hline $\begin{array}{l}\text { How easy or difficult was it to maintain the required speeds and meet the } \\
\text { segment RTA? } \\
(1=\text { Very Difficult, 5= Very Easy) }\end{array}$ & $\begin{array}{l}2.00 \\
\text { (Somewhat } \\
\text { Difficult) }\end{array}$ & $\mathrm{N}=5$ \\
\hline
\end{tabular}

\section{B. Manual Control with HUD/FARGO Display}

For the second task, the HUD display was provided to the participant in addition to the electronic clearance instructions and EMM display. The HUD provided feedback about the current groundspeed vs. required groundspeed, ETA vs. RTA, whether they should be throttling up or down, an indicator that showed the difference between ETA and RTA, as well as centerline indicators to make maneuvering the aircraft easier. Figure 5 depicts the symbology on the HUD for this control mode. The participants were directed to use the EMM only as a reference and not to pilot the aircraft using the map.

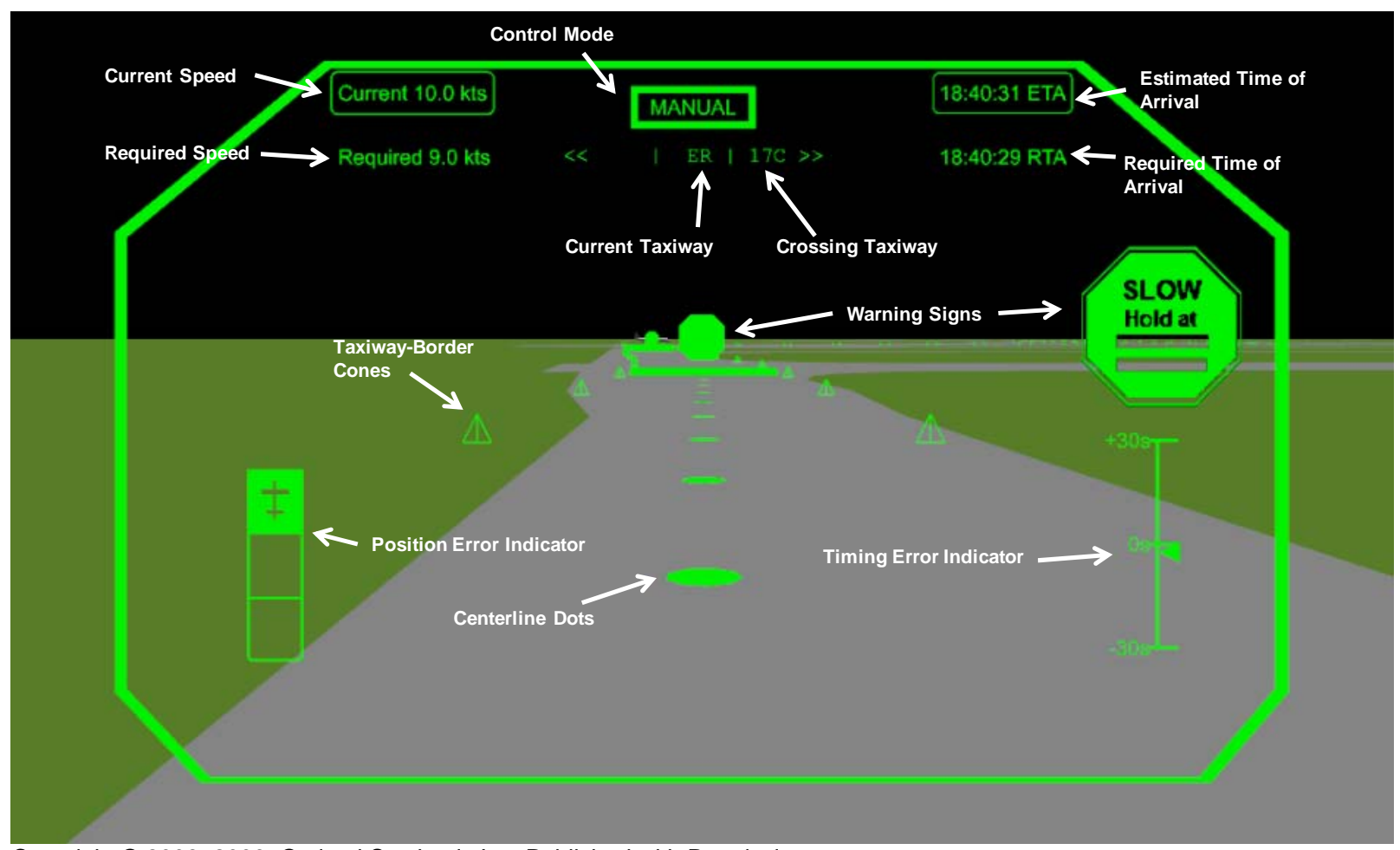

Copyright @ 2008-2009, Optimal Synthesis Inc. Published with Permission.

Figure 5. Sample HUD Display for Manual Control Mode

Overall the participants found the HUD to be very helpful in completing the taxi clearance successfully. HUD elements cited as particularly useful were the centerline maintenance graphic, the required/current speed indicator, 
and the numerical ETA/RTA indicator. Several participants noted that they picked a single indicator that was particularly useful to them (usually the Required vs. Current speed) and relied almost solely on that to guide their performance, paying much less attention to the other indicators.

The experimenter has observed the following:

- Participants consistently rated the "Manual Control with FARGO" condition higher than they did with "No FARGO." This validates the need for some kind of HUD system should a precision taxi system ever be implemented.

- Participants noted that the "Hold" indicators displayed in the out-the-window view frequently did not line up with the yellow markings on the ground, causing confusion, as well as some genuinely conflicting information (such as the "Slow 8kph" sign). These were attributed to errors in the code for the simulation environment and not part of the FARGO design.

\begin{tabular}{|c|c|c|}
\hline Task Ratings: & Mean Rating & $\mathbf{N}$ \\
\hline \multicolumn{3}{|l|}{ Practice Trial } \\
\hline $\begin{array}{l}\text { Q: How easy/difficult was it to navigate the route? } \\
\text { (1 Very Difficult - } 5 \text { Very Easy) }\end{array}$ & $\begin{array}{l}4.33 \\
\text { (Somewhat Easy) }\end{array}$ & $\mathrm{N}=6$ \\
\hline $\begin{array}{l}\text { How easy or difficult was it to maintain the required speeds and meet the } \\
\text { segment RTA? } \\
\text { (1=Very Difficult, } 5=\text { Very Easy) }\end{array}$ & $\begin{array}{l}4.33 \\
\text { (Somewhat Easy) }\end{array}$ & $\mathrm{N}=6$ \\
\hline \multicolumn{3}{|l|}{ Trial 1} \\
\hline $\begin{array}{l}\text { Q: How easy/difficult was it to navigate the route? } \\
\text { (1 Very Difficult - } 5 \text { Very Easy) }\end{array}$ & $\begin{array}{l}3.80 \\
\text { (Neutral to } \\
\text { Somewhat Easy) }\end{array}$ & $\mathrm{N}=5$ \\
\hline $\begin{array}{l}\text { How easy or difficult was it to maintain the required speeds and meet the } \\
\text { segment RTA? } \\
\text { (1=Very Difficult, } 5=\text { Very Easy) }\end{array}$ & $\begin{array}{l}4 \\
\text { (Somewhat Easy) }\end{array}$ & $\mathrm{N}=5$ \\
\hline \multicolumn{3}{|l|}{ Trial 2} \\
\hline $\begin{array}{l}\text { Q: How easy/difficult was it to navigate the route? } \\
\text { (1 Very Difficult - } 5 \text { Very Easy) }\end{array}$ & $\begin{array}{l}4.28 \\
\text { (Somewhat Easy) }\end{array}$ & $\mathrm{N}=7$ \\
\hline $\begin{array}{l}\text { How easy or difficult was it to maintain the required speeds and meet the } \\
\text { segment RTA? } \\
\text { (1=Very Difficult, } 5=\text { Very Easy) }\end{array}$ & $\begin{array}{l}4.14 \\
\text { (Somewhat Easy) }\end{array}$ & $\mathrm{N}=7$ \\
\hline
\end{tabular}

\section{Automatic Control with HUD/FARGO Display}

For their last task participants were shown the FARGO HUD being controlled by an algorithm for automated precision taxiing. The purpose of this task was to get further feedback about what indicators and on-screen displays were necessary for a pilot to safely monitor the automatic taxi system of an aircraft. Figure 6 depicts the symbology on the HUD for this control mode.

Most participants stated that the information displayed on the right-hand side of the HUD, relative to all of the control mechanisms of the plane, was unnecessary and in fact adding clutter to the interface. Rather, it was most important to be able to know exactly what the taxi system was supposed to be doing, and whether it was doing it correctly. For example, the user needs to know the taxi clearance plan, and be kept aware of whether the Auto-Taxi system is activated and performing correctly, or whether it is encountering errors. Common observations included:

- The plane component indicators are unnecessary. Participants stated that in a real plane all of the information would be available from other sources, and they did not need to monitor and be aware of every movement or control change the auto-taxi system made; they only needed to be aware of errors in those movements and how to correct them.

- Lack of an "Auto Taxi On” or some similar indicator to let them know that the system is engaged and working was cited as a major flaw.

- A "Distance to Next Checkpoint" or similar indicator was necessary to keep the user situationally aware and give them a means to determine if the Auto Taxi system is performing correctly. 
- Lack of an "Intent" indicator to let the user know the intent of other aircraft in the field of view. This was particularly disconcerting as other aircraft often seemed to be on a collision course, only to stop at the last second and let the participant pass. Several participants noted that a TCAS-like system would be very useful in the context of precision taxiing.

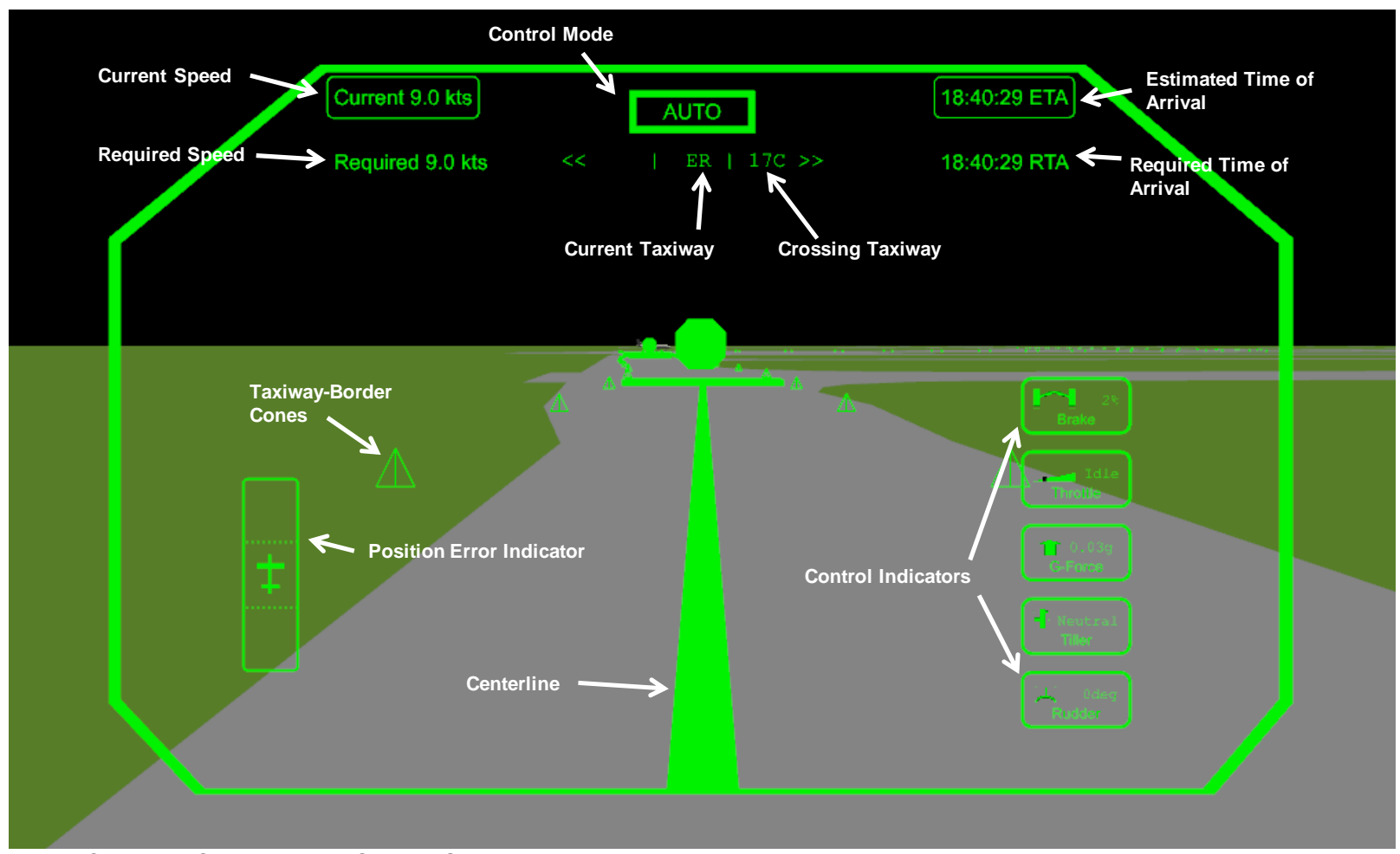

Copyright @ 2008-2009, Optimal Synthesis Inc. Published with Permission.

\section{Figure 6. Sample HUD Display for Auto-Taxi Mode}

\section{Post-Trial Discussion}

After interacting with all three conditions, participants were asked a series of post-trial questions to verify their overall impressions of the system and informational requirements of the HUD.

Overall, participants liked the idea of a precision taxi system and saw definite benefits in the form of less wait time, fuel savings, and overall airport efficiency. Participants felt strongly that the HUD played a crucial role in such a system, but that there were remaining improvements that could be made to the FARGO HUD to make it more usable and pilot-friendly. Most comments re-emphasized findings observed from the study, such as:

- Distance indicators are necessary to provide the user with more data to make decisions when taxiing.

- Aircraft intent indicators are also necessary to show the user what other aircraft within the field of view are planning to do, especially in a close-proximity precision taxi environment.

- Segment indicators and reminders of what step of the electronic clearance pattern the user is on would be helpful in keeping the user aware of the next steps in their taxiing.

- Many participants felt that a color HUD display could be used to greatly improve the informational density of the display, though they understood that current technology limitations would prevent that.

\section{Recommendations for Design Enhancements}

Based on participant comments, the following list of final design recommendations has been compiled.

- There were suggestions on timing and speed indicators to improve the pilot's ability to control the throttle of the aircraft in order to meet the timing constraints. They also identified some other HUD indicators as confusing and provided suggestions on how to improve them. 
- The participants had difficulty distinguishing between the contingency holds and full stops. They were unanimous in stating that Full Stop holds needed to be distinguished from Contingency Holds both graphically and in the terminology used to describe them.

- The participants said that they would like to see taxi route and segment information from the electronic map and clearance instructions in the HUD itself, to prevent them from having to constantly scan the cockpit and assimilate information from two disparate displays. In particular, information about the next segment of the taxi clearance pattern should be displayed in the HUD itself, as well as distance information for how far they are from the endpoint of that segment.

- The participants also provided suggestions on eliminating some of the displayed data for monitoring AutoTaxi performance, and on the need to provide information to improve the pilot's awareness of the Auto-Taxi system's state and compliance with the time-constrained clearance.

- Finally, participants noted that in a precision taxi environment, a crucial piece of information not currently provided by the HUD would be information about the distance, speed, and intent of other aircraft. Given that the goal of the precision taxi system is to greatly increase the density and movement of aircraft on the tarmac, pilots will need to be able to gauge the intent and predict the movement of other aircraft in their field of view to be able to comfortably maneuver their plane around them.

\section{Concluding Remarks}

A usability and information requirements study has been performed for the problem of pilot executing 4D trajectories on the airport surface. The goal of the study was to identify the information requirements for pilots to execute the 4D-trajectory clearances, to discover issues related to the general interface design and properties of the display, and to document specific improvements that could be made to the design of the display and how it communicates information to the user.

The study was performed using a prototype experimental automation system developed to help the pilot perform precision taxi based on 4D-trajectory clearances. The concept assumes the availability of a Head-Up Display (HUD) for conveying taxi control information to the pilot, allowing the pilot to maintain an out-the-window view while executing the 4D trajectory. The usability test focuses on the use of the HUD for conveying the taxi control information. Eight pilots participated in the study, and they ran three conditions of experiments for comparison: (i) no automation, (ii) manual control with automation providing advisory for vehicle control, and (iii) automation providing fully automatic control with the pilot monitoring the performance.

Overall, the participants found the idea of precision taxiing to be a good one which would greatly increase the overall efficiency of air travel. The HUD was seen as a crucial component to the idea of precision taxiing, and there was unanimous acknowledgement that precision taxiing would be impossible without it. This suggestion, however, has to be examined by taking the test method into consideration: The test only compared the use of the HUD to the case without the HUD, but did not consider the possibility of other forms of display; hence this suggestion should be interpreted as some form of display that carries comparable information as that on the HUD should be considered essential for precision taxiing. The participants also recommended a comprehensive list of design enhancements, which should be considered for inclusion in future research and development of the automation system. This list of recommendations includes not only the need to convey information for executing the 4D trajectories, but also the need to convey information on the intent of the nearby aircraft. As part of the Surface Operation Automation Research (SOAR) automation concept, the intent of the other aircraft can be made available from their respective 4D-trajectory clearances, which can also be received and used by the flight-deck automation on the own aircraft.

\section{Acknowledgments}

This research has been supported in part by NASA under Contract No. NNA06AA06C.

\section{References}

\footnotetext{
${ }^{1}$ Anon., “Concept of Operations for the Next Generation Air Transportation System,” v. 2.0, Joint Planning and Development Office, Washington, DC, June 13, 2007.

${ }^{2}$ Airport Surface Detection Equipment-Model X (ASDE-X), NAS Subsystem Level Specification, Version 1.1, Federal Aviation Administration, Washington DC, May 24, 2001.

${ }^{3}$ Scardina, J., "Overview of the FAA ADS-B Link Decision,” Office of System Architecture and Investment Analysis, Federal Aviation Administration, June 7, 2002.
} 
4 “AMASS Specifications,” FAA-E-2069a, Federal Aviation Administration, 2005.

${ }^{5}$ Eggert, J. R., B. R. Howes, M. Picardi Kuffner, H. Wilhelmsen, and D. J. Bernays, "Operational Evaluation of Runway Status Lights,” Lincoln Laboratory Journal, Vol. 16, No. 1, 2003.

${ }^{6}$ Foyle, D. C., A. D. Andre, R. S. McCann, E. M. Wenzel, D. R. Begault, and V. Battiste, "Taxiway Navigation and Situation Awareness (T-NASA) System: Problem, Design Philosophy, and Description of an Integrated Display Suite for Low-Visibility Airport Surface Operations,” SAE Transactions: Journal of Aerospace, Vol. 105, pp. 1411-1418, 1996.

${ }^{7}$ McCann, R. S., D. C. Foyle, B. L. Hooey, A. D. Andre, B. Parke, and B. Kanki, “An Evaluation of the Taxiway Navigation and Situation Awareness (T-NASA) System in High-Fidelity Simulation,” SAE Transactions: Journal of Aerospace, Vol. 107 , 1612-1625, 1998.

${ }^{8}$ Jones, D., "Runway Incursion Prevention System - Demonstration and Testing at the Dallas/Fort Worth International Airport,” Proceedings of the 20th Digital Avionics Systems Conference, Daytona Beach, FL, 2001.

${ }^{9}$ Young, S. D., and D. R. Jones, "Runway Incursion Prevention: A Technology Solution,” Proceedings of the Flight Safety Foundation 54th Annual International Air Safety Seminar, 54, 1-22, Athens, Greece: Flight Safety Foundation, 2001.

${ }^{10}$ Atkins, S., and C. Brinton, “Concept Description and Development Plan for the Surface Management System,” Journal of Air Traffic Control, 2002.

${ }^{11}$ Atkins, S., Y. Jung, C. Brinton, S. Stell, and S. Rogowski, “Surface Management System Field Trial Results,” Proceedings of the AIAA 4th Aviation Technology, Integration and Operations (ATIO) Forum, Chicago, IL, September 20-22, 2004, Paper AIAA 2004-6241.

${ }^{12}$ Cheng, V. H. L., "Collaborative Automation Systems for Enhancing Airport Surface Traffic Efficiency and Safety," Proceedings of the 21st IEEE/AIAA Digital Avionics Systems Conference, Irvine, CA, October 29-31, 2002, Paper 1D4.

${ }^{13}$ Cheng, V. H. L., "Airport Surface Operation Collaborative Automation Concept," Proceedings of the AIAA Guidance, Navigation, and Control Conf., Austin, TX, August 11-14, 2003, AIAA Paper 2003-5773.

${ }^{14}$ Cheng, V. H. L., "Surface Operation Automation Research for Airport Tower and Flight Deck Automation," Proceedings of the 2004 IEEE Intelligent Transportation Systems (2004 ITSC), Washington, DC, October 3-5, 2004, Paper TuC2.4.

${ }^{15}$ Cheng, V. H. L., "Research Progress on an Automation Concept for Surface Operation with Time Based Trajectories," 7th Integrated Communications, Navigation, and Surveillance (ICNS) Conference, Herndon, VA, May 1-3, 2007.

${ }^{16}$ Cheng, V. H. L., and D. C. Foyle, "Automation Tools for Enhancing Ground-Operation Situation Awareness and Flow Efficiency,” Proceedings of the AIAA Guidance, Navigation, and Control Conference, Monterey, CA, August 5-8, 2002, AIAA Paper 2002-4856.

${ }^{17}$ Cheng, V. H. L., V. Sharma, and D. C. Foyle, "Study of Aircraft Taxi Performance for Enhancing Airport Surface Traffic Control,” IEEE Transactions on Intelligent Transportation Systems, Vol. 2, No. 2, pp. 39-54, June 2001.

${ }^{18}$ Sweriduk, G. D., V. H. L. Cheng, A. D. Andre, and D. C. Foyle, “Automation Tools for High-Precision Taxiing," Proceedings of the $6^{\text {th }}$ Digital Avionics Systems Conference, Dallas, TX, October 21-25, 2007.

${ }^{19}$ Cheng, V. H. L., G. D. Sweriduk, C. H. Yeh, A. D. Andre, and D. C. Foyle, "Flight-Deck Automation for Collaborative Surface Operation Concept," Proceedings of the AIAA Guidance, Navigation, and Control Conf., Honolulu, HI, August 18-21, 2008.

${ }^{20}$ Cheng, S. Y., V. H. L. Cheng, Y. G. Seo, L. H. Martin, S. A. Verma, and D. S. Ballinger, "Ground Operation Concept Testing Requirements and Challenges,” to be presented, AIAA Modeling and Simulation Technologies Conference, Hilton Head, SC, Paper No. AIAA-2007-6701, August 20-23, 2007.

${ }^{21}$ Dorighi, N. S., and B. T. Sullivan, "FutureFlight Central: A Revolutionary Air Traffic Control Tower Simulation Facility," Proceedings of the AIAA Modeling and Simulation Technologies Conference, Austin, TX, 2003, Paper AIAA-2003-5598.

${ }^{22}$ Martin, L., S. Verma, D. Ballinger, and V. Cheng, "Developing a Decision Support Interface for Surface Domain Air Traffic Controllers," Proceedings of the Human Factors and Ergonomics Society's 51st Annual Meeting, Baltimore, MD, October 1-5, 2007.

${ }^{23}$ Verma, S., T. Kozon, V. Cheng, and D. Ballinger, "Changes in Roles/Responsibilities of Air Traffic Control under Precision Taxiing,” 26 ${ }^{\text {th }}$ Digital Avionics Systems Conference, Dallas, TX, October 21-25, 2007.

${ }^{24}$ Rathinam, S., J. Montoya, and Y. Jung, “An Optimization Model for Reducing Aircraft Taxi Times at Airports,” $26^{\text {th }}$ Congress of International Council of the Aeronautical Science, Anchorage, AK, September 14-19, 2008, Paper ICAS 20088.6.1.

${ }^{25}$ Tsao, H.-S. J., W. Wei, A. Pratama, and J. R. Tsao, "Integrated Taxiing and Take-Off Scheduling for Optimization of Airport Surface Operations,” Proc. 2nd Annual Conference of Indian Subcontinent Decision Science Institute (ISDSI 2009), Mumbai, India, Jan. 3-5, 2009.

${ }^{26}$ Foyle, D. C., J. L. Williams, and B. L. Hooey, "Toward the Development of Information Requirements of Time-Based (4D) Taxi Clearances: Pilot-in-the-loop Results,” NASA Airspace Systems Program Technical Interchange Meeting, Austin, TX, March 18-20, 2008.

${ }^{27}$ Foyle, D. C., B. L. Hooey, C. L. Kunkle, M. F. J. Schwirzke, and D. L. Bakowski, "Piloted Simulation of NextGen Timebased Taxi Clearances and Tailored Departures,” Proceedings of the 2009 IEEE/AIAA Integrated Communications, Navigation and Surveillance Conference (ICNS), Arlington, VA, May 13-15, 2009.

${ }^{28}$ Jones, D. R., “Collision Avoidance for Airport Traffic (CAAT),” NASA Airspace Systems Program Technical Interchange Meeting, Austin, TX, March 18-20, 2008. 
${ }^{29}$ Meier, C., J. Jakobi, P. Adamson, S. Lozito, and L. Martin, "Benefits of Advanced Surface Movement Guidance and Control Systems (A-SMGCS),” Air Traffic Control Quarterly, Vol. 13, No. 4, pp. 329-356, 2006.

${ }^{30}$ Smeltink, J. W., M. J. Soomer, P. R. de Waal, and R. D. van der Mei, “An Optimisation Model for Airport Taxi Scheduling,” Technical Report, National Aerospace Laboratory NLR, June 11, 2004.

31“Operational Requirements Document (ORD-Update)," Document No. D1.3.5, Version No. 1.0, European Airport Movement Management by A-SMGCS (EMMA), April 25, 2006.

${ }^{32}$ Moller, M., "EMMA Air-Ground Operational Service and Environmental Description (OSED-update)," Document No. D1.3.1.u, Version No. 1.0, European Airport Movement Management by A-SMGCS (EMMA), April 25, 2006. 